\title{
ISO 50001 NORMA MUNDIAL PARA A EFICIÊNCIA ENERGÉTICA.
}

\section{PORQUÊ UMA NORMA MUNDIAL?}

\section{Introdução}

Nem sempre são fáceis os desafios ambientais associados ao consumo de energia. Sobretudo devido à forte dependência de combustíveis fósseis, torna-se cada vez mais evidente a inevitabilidade de agentes económicos, políticos, sociedade em geral, assumirem um compromisso focado na melhoria da eficiência energética e no uso racional da energia, decorrente das atividades económicas.

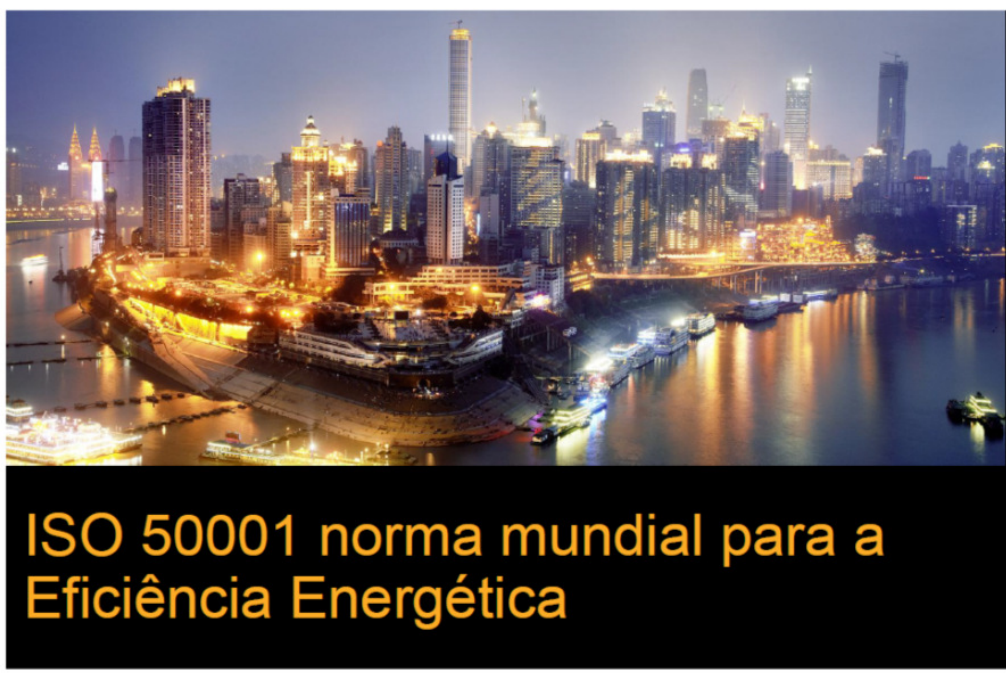

ABB

Esta preocupação assume-se também como nacional. A norma NP EN ISO 50001 apresenta-se como uma solução de método transversal e de harmonia internacional. Vetores como gestão eficiente de energia, consequente minimização no impacto ambiental e relevantes reduções dos custos de energia, são os pilares desta norma que certifica atividades desde o sector terciário ao industrial.

Portugal dispõe de regulamentação diversa neste âmbito, podendo a referida norma ser o "chapéu" que abraça os demais conteúdos relacionados com a energia. Desde normas do CENELEC, em concreto a EN 15232 (Eficiência Energética nos Edifícios - Impacto da Automatização de Edifícios, Controlos e Gestão dos Edifícios), diretivas europeias 2002/91/EC (Eficiência Energética da Diretiva de Edifícios EPBD - Energy Performance of Buildings (www.epbd-ca.eu)) transpostas para o direito nacional através do DL 79/2006, que nos levam à regulamentação RSECE (Regulamento dos Sistemas Energéticos de Climatização nos Edifícios), até outras igualmente pertinentes, nomeadamente SCE (Sistema de Certificação de Edifícios (DL 78/2006)), RCCTE (Regulamento das Características de Comportamento Térmico dos Edifícios (DL 80/2006)), SGCIE (Sistema de Gestão dos Consumos
Intensivos de Energia (DL 71/2008)), PNAEE (Plano Nacional de Ações para a Eficiência Energética (Resolução Conselho de Ministros 20/2013)) e PNAER (Plano Nacional de Ação para as Energias Renováveis (Diretiva 2009/28/CE)).

Mais recentemente, a Portaria 349-D/2013, de 2 de Dezembro, que estabelece os requisitos de conceção para edifícios novos e intervenções no que diz respeito ao desempenho energético no terciário, reforçando, no capítulo 10, a importância da contagem de energia no tema climatização.

$A \mathrm{ABB}$, para além de promover junto dos seus clientes, como valor acrescentado, a Eficiência Energética, disponibiliza um conjunto de ferramentas que contribuem para o cumprimento dos vários passos duma Certificação NP EN ISO 50001. Numa lógica "Plan-Do-Check-Act" (Jornada Técnica ISO 50001 - Norma Mundial para a Eficiência Energética, http://pt.inside.abb.com), apresenta-se como fornecedor de soluções, desde a monitorização e medida até à implementação das ações preventivas e corretivas, socorrendo-se de hardware de tecnologia de ponta e de softwares dedicados de algoritmos adaptados ao perfil do cliente. 


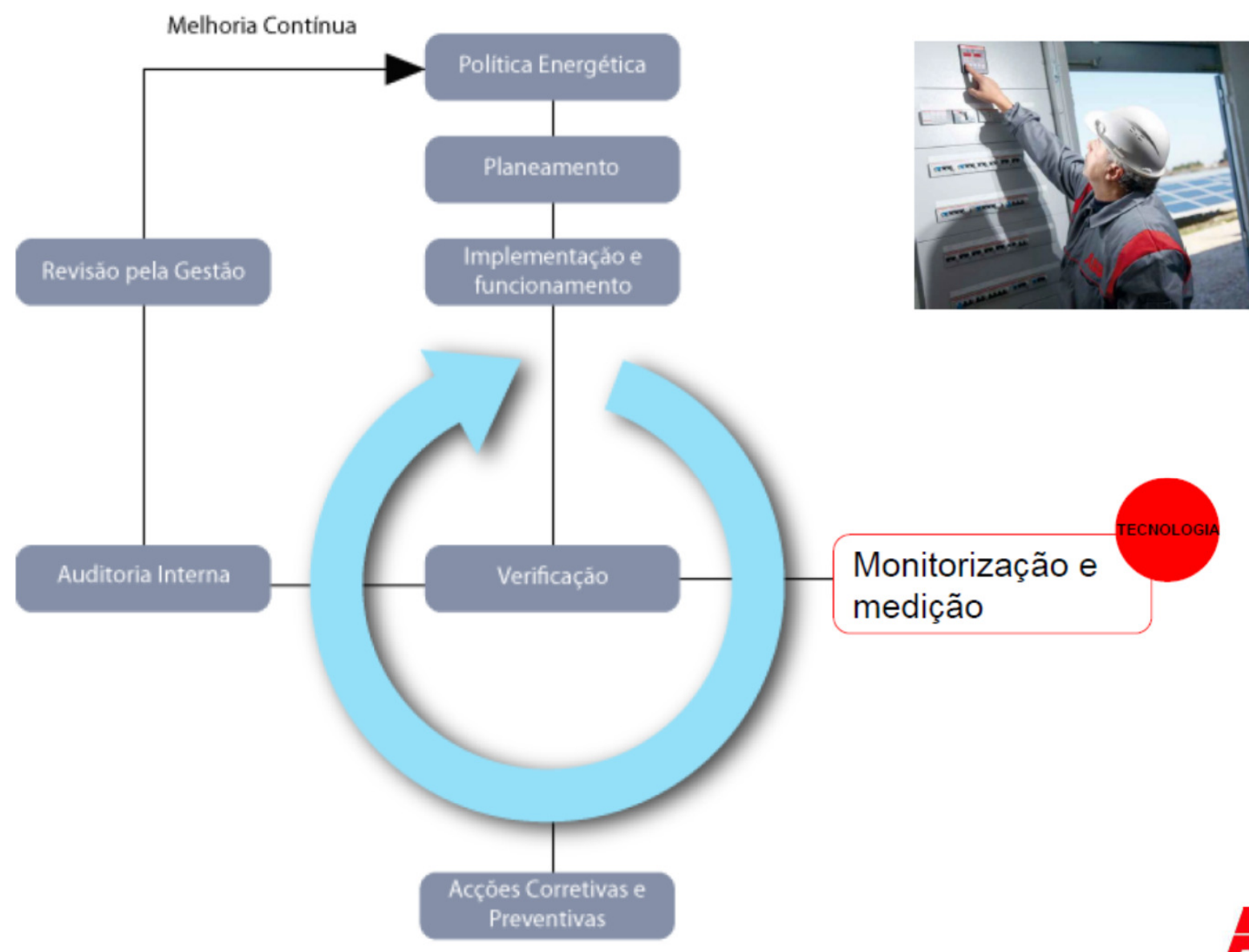

ABB

Na presente norma, no capítulo monitorização e medição, a ABB destaca a mais recente solução CMS - "Current Measurement System".

O CMS é um sistema de medição de corrente multicanal para monitorização de secções de corrente AC e DC. Um sistema diferenciador e singular, as duas tensões numa só tecnologia. A medição de correntes em unidades de distribuição de potência (PDUs), muito próximo de cargas elétricas, aumenta a eficiência e a disponibilidade de todas as instalações.

A qualidade do sistema de medição de corrente é determinada pela interação perfeita e pela força de todas as suas partes individuais. É aqui que o sistema CMS da ABB se sobrepõe e se apresenta como uma solução eleita: devido ao seu tamanho compacto, tecnologia, resultados da medição, facilidade de utilização e flexibilidade - todos os componentes e funcionalidades do CMS estão otimizados em perfeição para a aplicação e funcionamento práticos. 


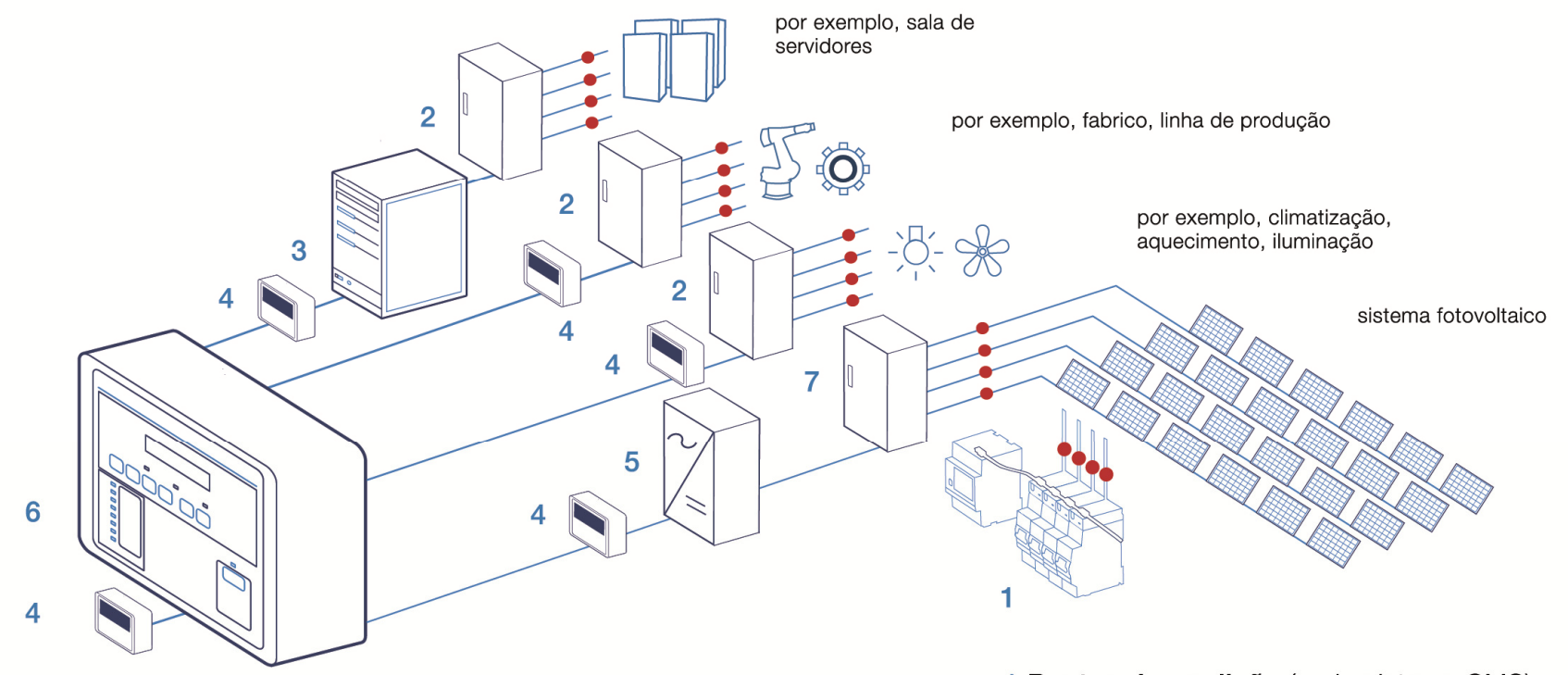

1 Pontos de medição (• do sistema CMS) 2 Sub-distribuição 3 Sistema UPS

4 Medidores de energia

5 Inversor de potência

6 Distribuição principal

7 Quadro de Campo (CC)

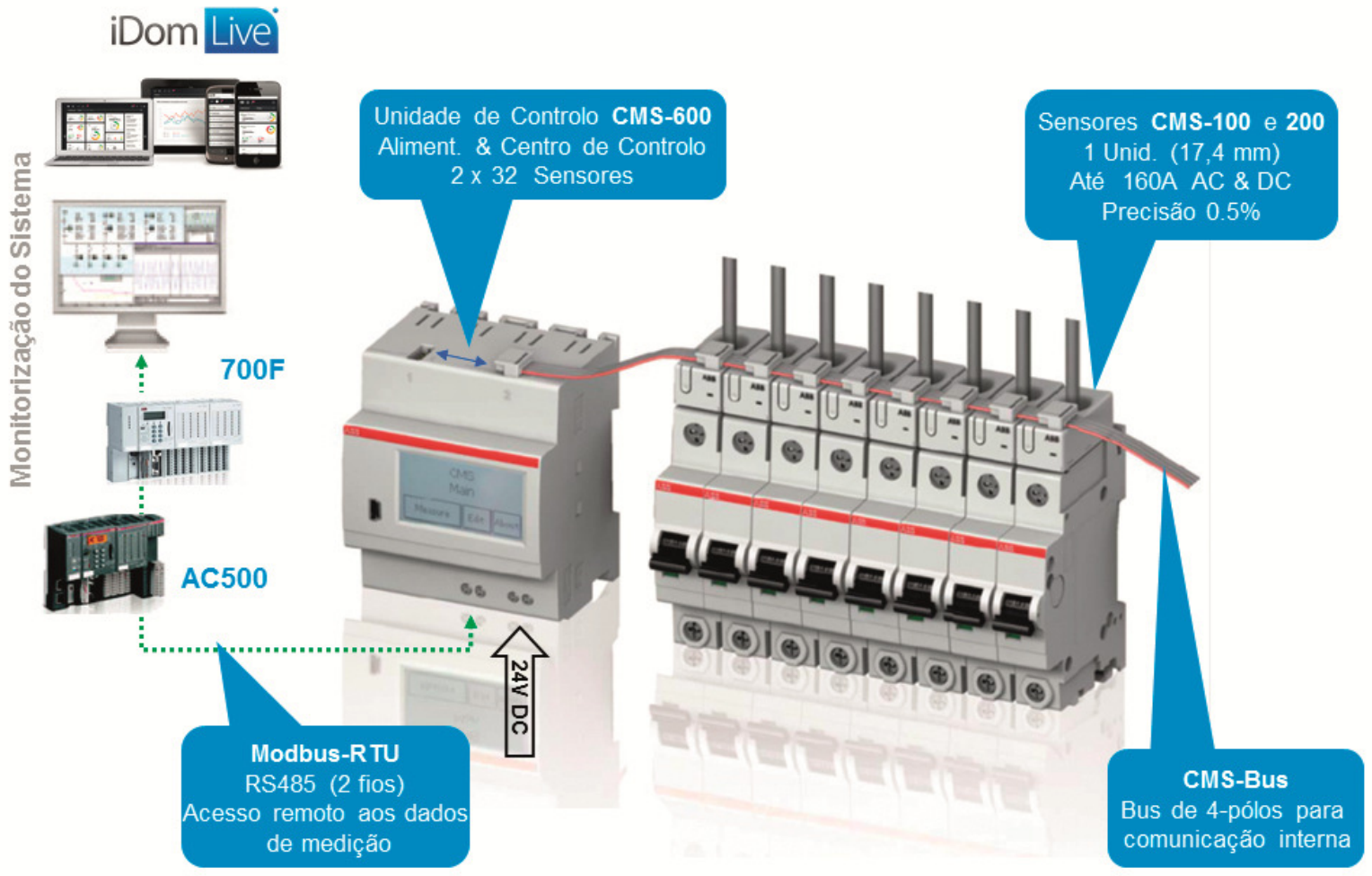


O sistema está estruturado com DOM^Tı́n iDom Live base numa unidade de controlo CMS-600 e sensores CMS-100 e

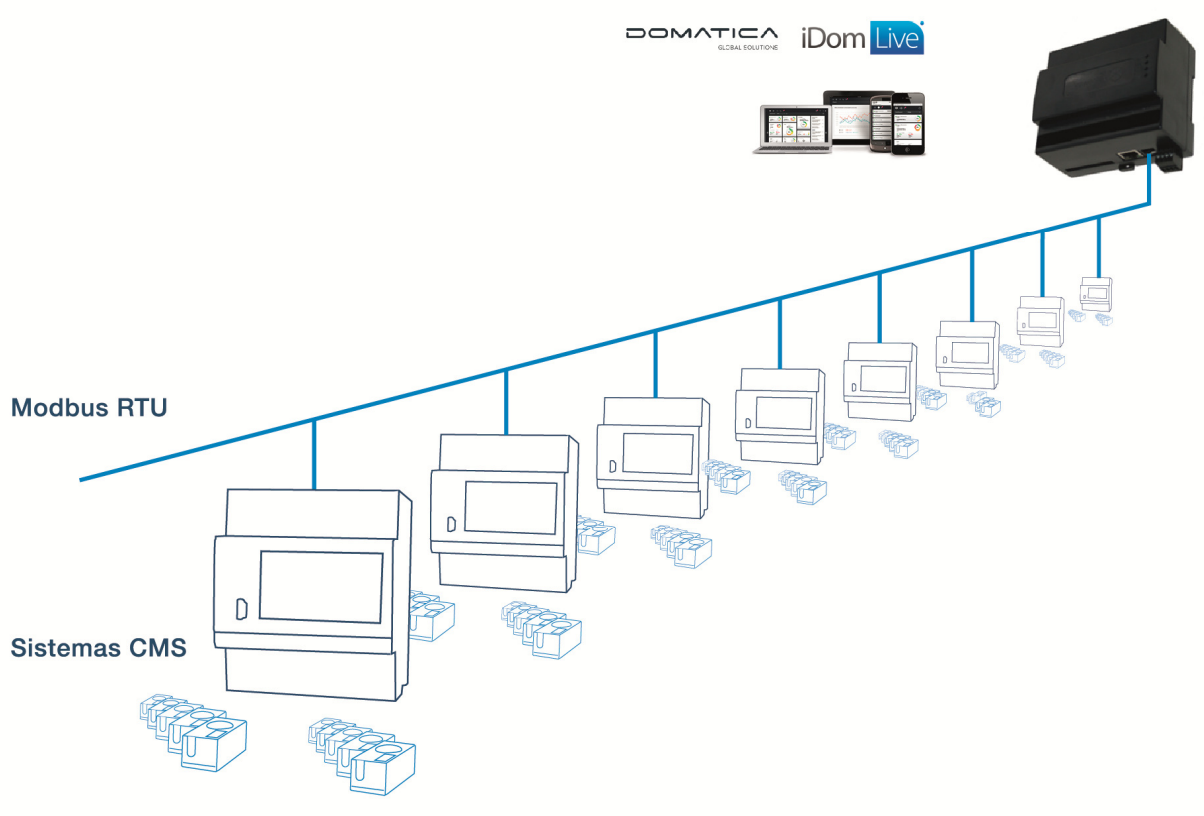
200 , de calibres de $20,40,80$ e 160a , tanto em AC como DC (TRMS).

Os sensores estão conectados à unidade CMS-600 em Bus, garantido por "flat cable" CMSBus a 4 fios, dedicados à alimentação do sistema (9V) e comunicação entre as unidades de controlo CMS-600 e os sensores CMS-100 e 200.

O sistema considera até 64 sensores por Unidade de Controlo, distribuídos $32+32$ por 2x CMS-Bus.

A unidade CMS-600 recolhe o valor de corrente dos sensores associados à arquitetura do sistema definido para o projeto, isto é, o número de sensores versus cargas monofásicas e trifásicas. A informação é guardada na eletrónica do sistema. Através da saída RS485 Modbus, as medidas poderão ser disponibilizadas para uma qualquer gestão tipo "BMS Building management system"(autómato AC500, DCS 700F entre outros hardwares e plataformas de automação $A B B$ ) ou ainda outras tecnologias e softwares dedicados conforme a solução iDomLive.
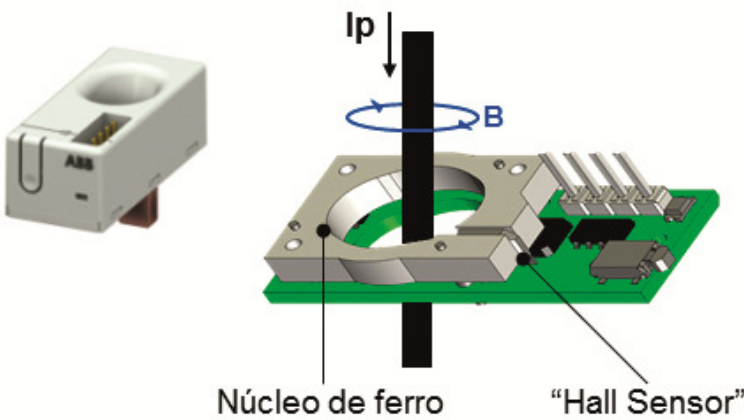

Os sensores CMS baseiam-se no efeito "open loop", conseguido pela tecnologia oferecida pelo efeito "hall sensor". Estes permitem medir corrente AC e DC, com a devida separação galvânica entre primário e secundário.

Com as componentes DC cada vez mais presentes nas instalações elétricas, fruto da eletrónica de potência nas cargas não lineares (VEV, UPS, inversores solares, carregamento de VE, etc.), a tecnologia que se apresenta é a resposta à necessidade de medidas reais para as tomadas de decisões coerentes.

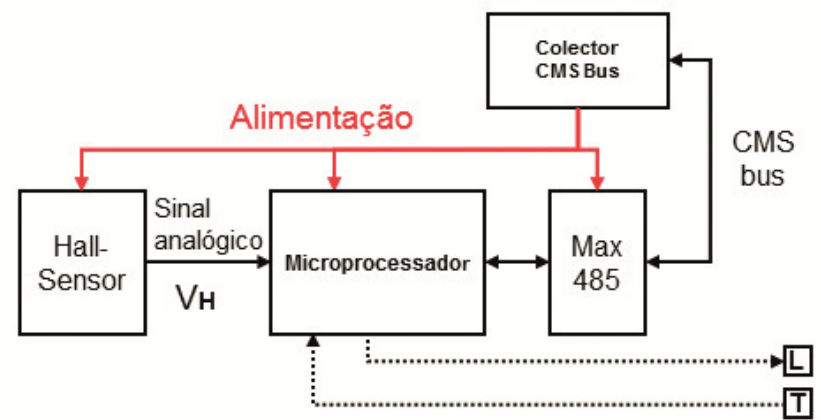


A corrente primária (Ip) flui no núcleo do sensor criando um fluxo magnético (B). As lâminas de ferro macio por acoplamento são sensibilizadas pelo fluxo criado. O "hall sensor" colocado no espaço de ar do núcleo de ferro gera uma tensão (VH) proporcional a esse fluxo, que por sua vez é proporcional à corrente (Ip) a ser medida. O microcontrolador processa o sinal e disponibiliza-o em valor digital no CMS-bus. A Lei de Ampére ajuda-nos a justificar o princípio apresentado, uma vez que se verifica a relação entre uma corrente e o campo magnético que esta corrente produz.

\section{Uso amigável}

Da instalação à entrada em serviço, a solução CMS responde com rapidez, fiabilidade e flexibilidade. Medições em poucos minutos de forma local e intuitiva. Reforçada remotamente através Modbus RS485.

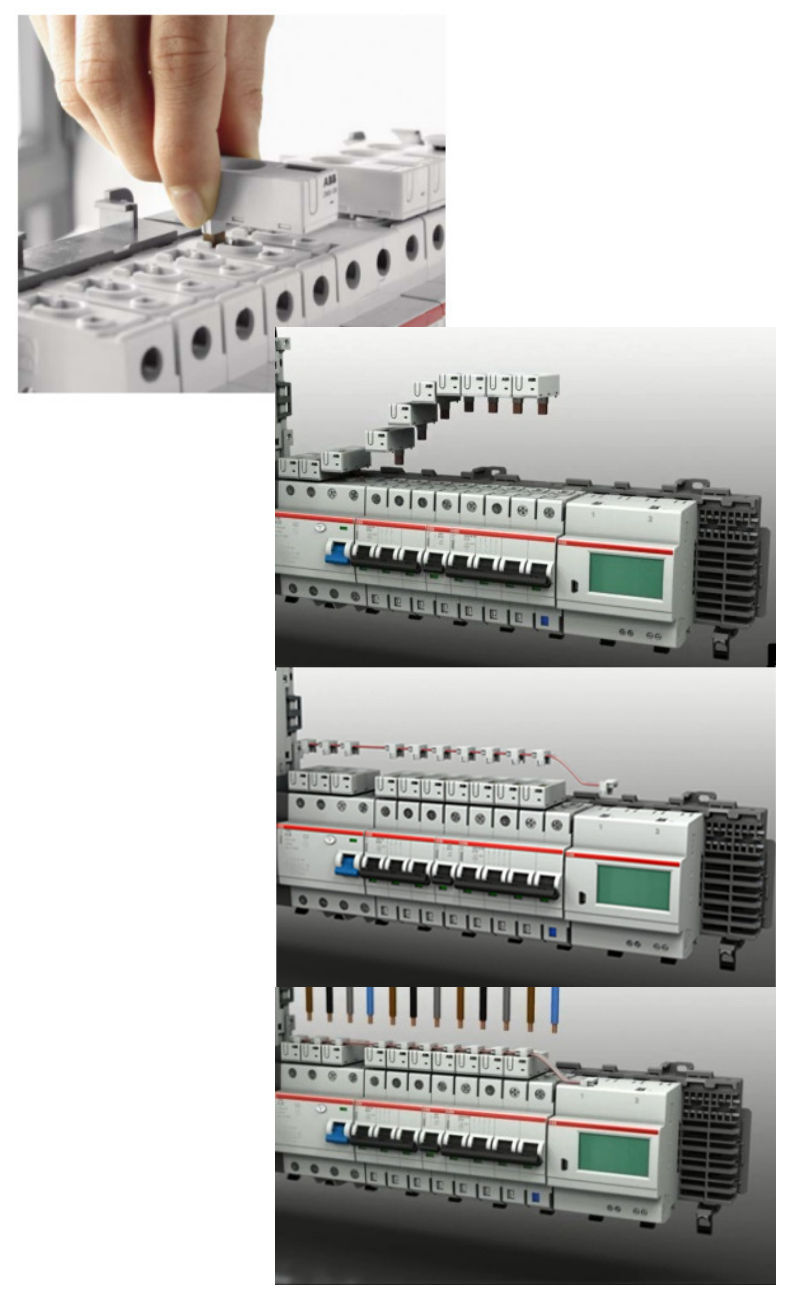

Smissline TP-Touch proof system

\section{Em harmonia com a proteção de circuitos}

Harmonia perfeita em instalações novas, face à compatibilidade de acessorização com as gamas modulares da ABB, System pro $M$ compact $^{\circledR}$, até $63 \mathrm{~A}$, e Smissline TP (RTIEBT [I] 412 - Proteção contra contactos diretos), ou resposta às oportunidades de renovação (DL 32/2012, Portaria 349-D/2013) optando pela solução em calha DIN e/ou cabo.
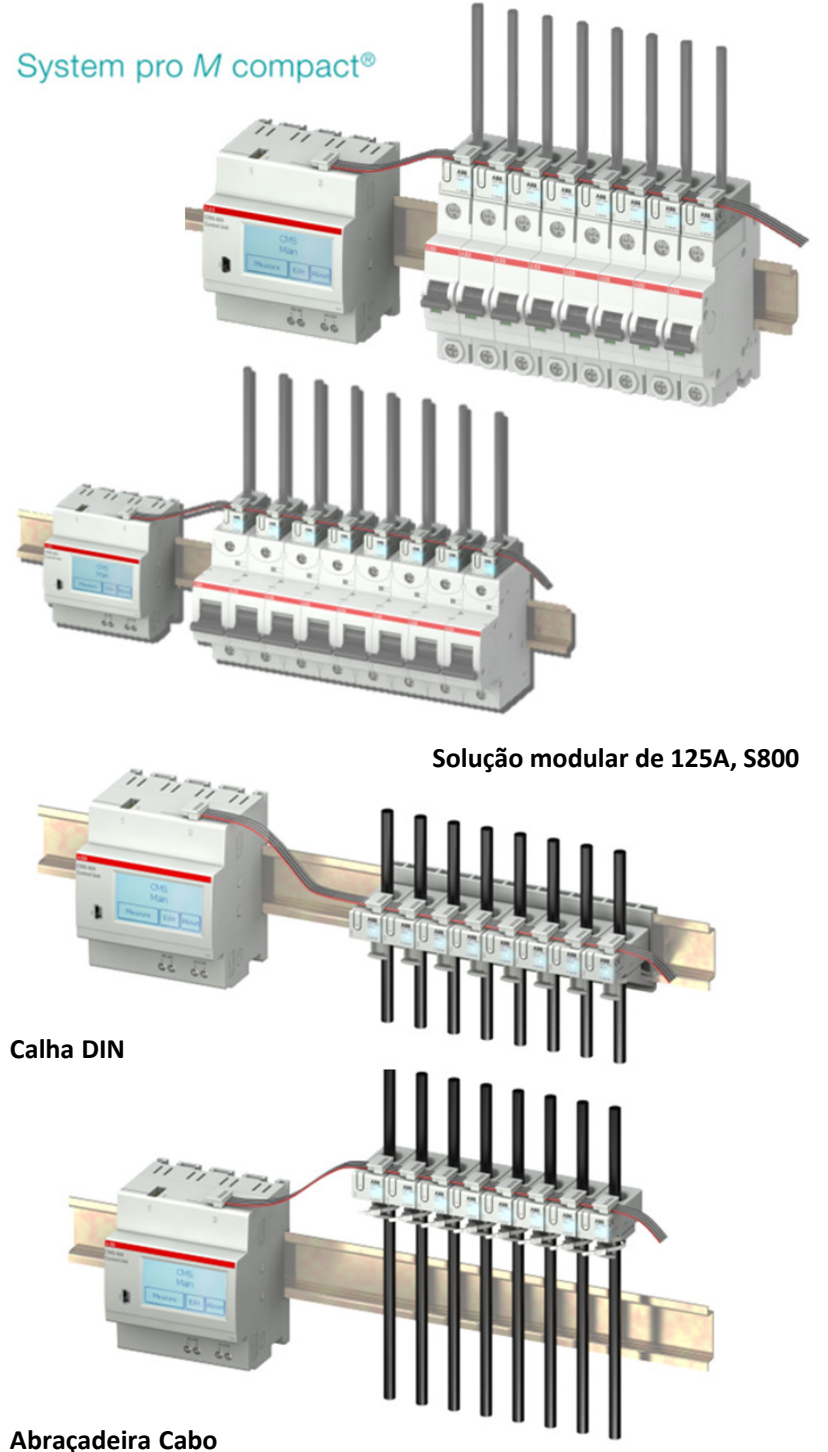

Abraçadeira Cabo

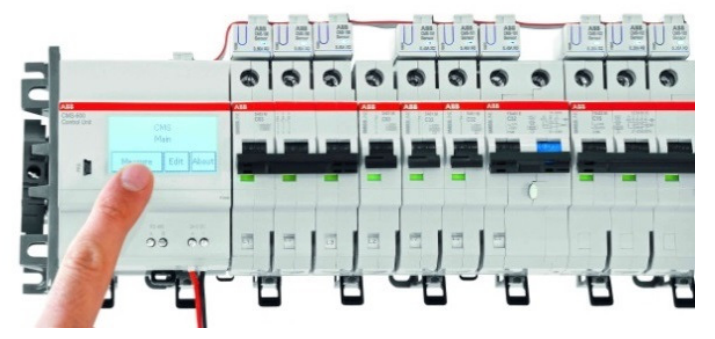




\section{Aviso de Sobrecarga}

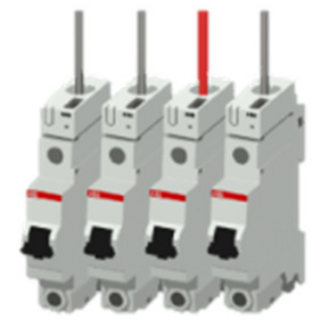

Ampliações ou renovação de instalações elétricas podem causar mudanças de carga nas linhas de alimentação. Uma linha em sobrecarga provoca a abertura da unidade funcional dedicada à proteção contra sobreintensidades. As perdas financeiras associadas podem ser evitadas pelo controlo permanente através do CMS.

\section{Monitorização de carga}

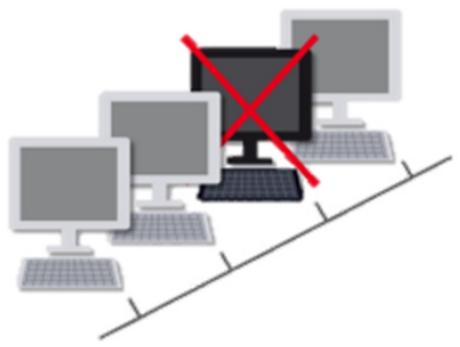

O controlo de circuitos individuais informa-nos se todas as cargas estão no modo de operação desejado. Desta forma, o utilizador pode atuar em conformidade com as exigências de exploração do projeto, prevenindo ou informando remotamente a manutenção, garantindo reação rápida ou preventiva a falhas, e evitando a paragem de produção ou de processos de trabalho.

\section{Monitorização da fase}

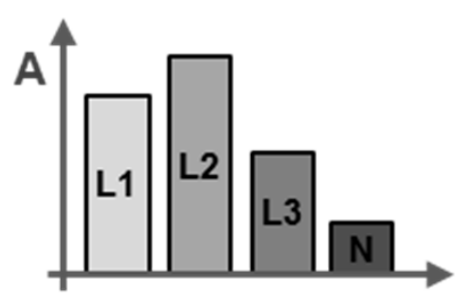

Fases desequilibradas causam correntes no neutro, que podem levar à rutura do condutor neutro, quando a sua corrente máxima (Iz) é ultrapassada. Cargas monofásicas não podem operar sem o neutro, podendo inclusivamente danificar equipamentos. Esta falha pode ser facilmente detetada pela monitorização constante do neutro e das correntes de fase por parte do CMS.

\section{Poupança pela transparência}

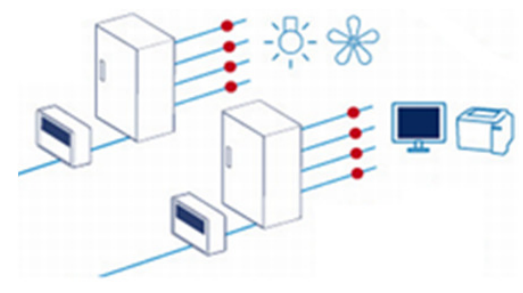

“Não é possível melhorar o que não se pode medir!"

Para utilizar a energia elétrica de forma eficiente e eficaz, primeiro deve ser claro onde e como deve ser usada. A monitorização da corrente de cada circuito de uma instalação dá-nos a máxima transparência para detetar os consumos de correntes inúteis e os dispositivos que necessitam de mais potência.

\section{Divisão de custos}

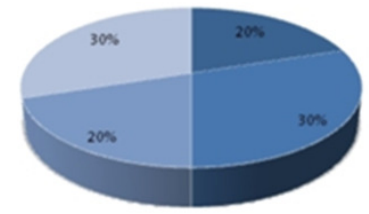

Se um edifício, um departamento, uma ala, é partilhada, muitas vezes utiliza-se a divisão dos custos da energia por metro quadrado. A soma das correntes dos respetivos circuitos representa um fator de divisão mais preciso e mais justo.

A solução CMS responde em conformidade e alinhamento com o foco na eficiência energética, ao apresentar-se como uma ferramenta de apoio à certificação NP EN ISO 50001. Pela sua flexibilidade, adapta-se quer ao projeto novo quer de ao de reabilitação, sobretudo pela sua dimensão e consequente uso em quadros elétricos com reservas já ocupadas ou no limite. Sensores de calibres até 160A em AC e DC respondem aos mais comuns requisitos do perfil de cargas de fim de linha, típicas no terciário e indústria. Leituras fáceis localmente e/ou remotamente, numa solução segura sem conexão direta, tirando partido da leitura por "campo gerado" com uma precisão interessante.

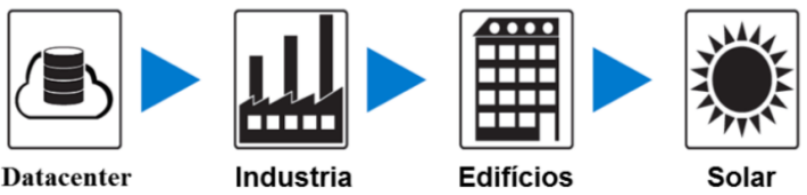

